\title{
INTRATHECAL ADJUVANTS IN SPINAL ANAESTHESIA FOR LOWER ABDOMINAL GYNAECOLOGICAL SURGERIES
}

\author{
Rani Vasantha Kumari Shunmugavelu1, Chithra Devi Ramakrishnan² \\ ${ }^{1}$ Assistant Professor, Department of Anaesthesia, Government Theni Medical College, Theni. \\ ${ }^{2}$ Assistant Professor, Department of Anaesthesia, Government Theni Medical College, Theni.
}

\section{ABSTRACT}

\section{BACKGROUND}

The aim of this study was to assess the effectiveness of the administration of fentanyl and midazolam in spinal anaesthesia for lower abdominal gynaecological surgeries.

\section{MATERIALS AND METHODS}

75 patients were recruited to receive either $3.5 \mathrm{~mL}$ of $0.5 \%$ hyperbaric bupivacaine $+20 \mu$ of fentanyl (Group F) or $3.5 \mathrm{~mL}$ of $0.5 \%$ hyperbaric bupivacaine $+2 \mathrm{mg}$ of midazolam (Group M) or $3.5 \mathrm{~mL}$ of $0.5 \%$ hyperbaric Bupivacaine $+0.4 \mathrm{~mL}$ of normal saline (Group S).

\section{RESULTS}

There were no significant differences in the highest analgesic level between the groups. Two segment regression time was prolonged in adjuvants Group F and Group M when compared to Group S ( $<<0.00001$ for Group F and p $<0.0001$ for Group M). Duration of analgesia was significantly prolonged with adjuvants with Group F and M than with Group S (129.4 mins. Vs 233.8 for Group F and 187 for Group (M) P < 0.0001). Group F and M showed significantly lower median VNS pain scores than Group S (0 Vs $3, \mathrm{p}-0.004)$. There were no significant differences in the incidence of nausea, vomiting, hypotension, bradycardia, urinary retention. No patient developed respiratory depression or PDPH. The patient's satisfaction of spinal anaesthesia was $100 \%$ with Group F and M and 80\% in Group S.

\section{CONCLUSION}

Intrathecal adjuvants like $20 \mu$ Fentanyl or $2 \mathrm{mg}$ midazolam significantly improved the quality of analgesia. It prolonged the duration of bupivacaine in spinal anaesthesia and delayed the analgesic requirement in the early post-operative period.

\section{KEYWORDS}

Intrathecal, Fentanyl, Midazolam, Spinal Anaesthesia, Postoperative.

HOW TO CITE THIS ARTICLE: Shunmugavelu RVK, Ramakrishnan CD. Intrathecal adjuvants in spinal anaesthesia for lower abdominal gynaecological surgeries. J. Evolution Med. Dent. Sci. 2016;5(88):6580-6583, DOI: 10.14260/jemds/2016/1487

\section{BACKGROUND}

Spinal anaesthesia is commonly employed for lower abdominal gynaecological surgeries. The advantage of spinal anaesthesia includes simplicity of technique, its rapid onset and exclusion of aspiration.

Fentanyl is a phenylpiperidine derivative, synthetic opioid agonist that is structurally related to meperidine. As an analgesic, fentanyl is 75 to 125 times more potent than morphine. Fentanyl has a more rapid onset and shorter duration of action. Rapid onset is due to its high lipophilicity and shorter duration of action is due to its rapid redistribution to inactive sites, such as fat and skeletal muscles; $75 \%$ of initial fentanyl dose is undergoing first-pass pulmonary uptake. Fentanyl in continuous infusion causes progressive saturation of inactive tissue site. As a result, plasma concentration of fentanyl does not decrease rapidly. So the duration of analgesia may be prolonged in infusion.

Financial or Other, Competing Interest: None.

Submission 18-09-2016, Peer Review 22-10-2016,

Acceptance 28-10-2016, Published 03-11-2016.

Corresponding Author:

Dr. Rani Vasantha Kumari Shunmugavelu,

W/o. Dr. K. Paraman,

Anbu Clinic,

Velappar Kovil Street,

Aundi Patti,

Theni District,

Tamilnadu.

E-mail: drparamanrani62@gmail.com

DOI: $10.14260 /$ jemds/2016/1487
Fentanyl is metabolised by $\mathrm{N}$-demethylation, producing norfentanyl which is excreted by the kidney. Carotid baroreceptor reflex control of heart rate is markedly depressed by fentanyl. Bradycardia is more prominent with fentanyl and may lead to occasional reduction in blood pressure and cardiac output. Seizure activity has been described to follow rapid intravenous administration of fentanyl. In the absence of EEG, it is difficult to distinguish opioid-induced skeletal muscle rigidity or myoclonus from seizure activity. Administration of fentanyl to head injury patients has been associated with modest increase in intracranial pressure, which is accompanied by decrease in mean arterial pressure and cerebral perfusion pressure. Analgesic concentration of fentanyl greatly potentiates the effects of midazolam and decrease the dose requirements of propofol. The opioid-benzodiazepine combination displays marked synergism with respect to hypnosis and depression of ventilation.

Midazolam is an imidobenzodiazepine, which is water soluble. Once midazolam enters into the body, the $\mathrm{pH}$ changes to 7.4 and drug assumes closed ring structure and becomes highly lipid soluble. After intravenous administration of midazolam, the disappearance of midazolam from plasma proceeds into two distinct phases.

The initial phase of rapid disappearance is principally due to distribution of the drug while the final and slower phases of disappearance is attributable mainly to biotransformation. Midazolam is metabolised by hepatic microsomal oxidative mechanism by a process of hydroxylation to 1 and 4 
hydroxymidazolam and excreted in urine. GABA is an inhibitory neurotransmitter in brain and glycine is an inhibitory neurotransmitter in spinal cord and brainstem. The benzodiazepines augments GABA thus producing sedation, analgesia and anticonvulsant, while anxiolysis and muscle relaxation appear to be due to glycine mimetic effects in spinal cord and brainstem. Midazolam decreases the anaesthetic requirement of inhalational agents. Midazolam decreases the myocardial contractility and systemic vascular resistance and causes vasodilatation, thus causing fall in arterial pressure. Midazolam causes dose dependent depression of ventilation. Apnoea produced by midazolam is common in patients to premedicate with opioids, chronic obstructive pulmonary disorder and following faster injection of the drug. Their respiratory depression is reversed by flumazenil, but not by naloxone.

Fentanyl and Midazolam are well known for its rapid onset and shorter duration of action following intrathecal administration.

This study was designed to evaluate the effects of intrathecal fentanyl $20 \mu$ and midazolam $2 \mathrm{mg}$ on the improvement of analgesia of hyperbaric Bupivacaine in patients with lower abdominal gynaecological surgeries.

\section{MATERIALS AND METHODS}

The study was conducted in 75 patients posted for elective surgeries after getting approval from the Ethical Committee of Department of Anaesthesiology. Govt. Theni Medical College, Theni. Informed consent was obtained after explaining the procedure.

\section{Inclusion Criteria}

1. Adult patients aged 30 - 55 yrs.

2. ASA physical status I.

3. Cases like lower abdominal gynaecological surgeries.

\section{Exclusion Criteria}

1. ASA physical status II, III, IV.

2. Allergic to local anaesthetic.

3. Past history of severe headache.

4. Inability to qualify Pain by Verbal Numeric Scale (VNS).

\section{Patients are divided into 3 Groups -}

Group S, Group F, Group M.

Each group has 25 patients. All patients received Inj. Atropine $0.6 \mathrm{mg} \mathrm{IM}, 45 \mathrm{mins}$. before surgery.

Group S (n = 25) - Received $17.5 \mathrm{mg}$ of $0.5 \%$ Bupivacaine + $0.4 \mathrm{~mL}$ of NS

Group F (n = 25) - Received $17.5 \mathrm{mg}$ of $0.5 \%$ Bupivacaine + $20 \mu(0.4 \mathrm{~mL})$ of Fentanyl.

Group M ( $\mathbf{n}=\mathbf{2 5})$ - Received $17.5 \mathrm{mg}$ of $0.5 \%$ Bupivacaine + $2 \mathrm{mg}(0.4 \mathrm{~mL})$ of Midazolam.

Total drug volume in all three groups is $3.9 \mathrm{~mL}$.

\section{Procedure}

Patients were explained about the procedure. Baseline PR, BP and RR were recorded. IV line secured with 18 gauge cannula. Preloading was done with $15-20 \mathrm{~mL} / \mathrm{kg}$ of crystalloid solution. Emergency drugs and equipment were kept ready. Patients were put on right lateral position under strict aseptic precaution. Subarachnoid block was performed with 25guage Quincke needle in $\mathrm{L}_{3}-\mathrm{L}_{4}$ interspace. After ensuring free flow of CSF, the drug was injected as per the group assigned. After injecting the drug, the patients were turned supine.

\section{Recording Data}

1. Time of giving subarachnoid block.

2. Time of onset of sensory block at $\mathrm{T}_{10}$ level.

3. Maximum level of sensory block achieved (By pinprick method).

4. Time of onset of maximum level of sensory block.

5. Time of onset of surgery.

6. $\mathrm{PR}, \mathrm{BP}, \mathrm{RR}, \mathrm{SpO}_{2}$ were monitored every 5 mins. for the first 15 mins., thereafter every 10 mins. for rest of the surgery and every 30 mins. in the postoperative period.

7. Hypotension was said to have occurred if there was a fall in BP $30 \%$ from baseline. This was treated with $100 \% \mathrm{O}_{2}$ through face mask, IV fluids and Inj. Ephedrine in titrated doses.

8. Level of consciousness was assessed and graded according to sedation score (Brain and Ready).

0 - Fully awake.

1- Normal sleep.

2- Drowsy, arousable on touch.

3- Drowsy, arousable to painful stimuli.

4- Somnolent.

9. Two segment regression time was noted.

10. Occurrence of pruritus noted.

11. Duration of analgesia. It was defined as that period from the time of giving the intrathecal anaesthesia till the patient's first requirement of systemic medication of analgesics.

12. The patient was asked to quantify their most intraoperative pain by using VNS pain score with -

0 - No pain.

1-3 - Mild pain.

4-6 - Moderate pain.

$>6$ - Severe pain.

13. Itching by 4 point rating Score -
0 - No itching.
1- Mild itching.
2- Moderate itching, Rx not required.
3- Severe itching, Rx required.

14. Nausea and vomiting by 4 point rating Score -
0 - No nausea and vomiting.
1- Nausea.
2- Retching.
3- Vomiting

15. The episodes of PDPH, urinary retention and patient's satisfaction of spinal anaesthesia were also recorded.

The Statistical significance was brought by Student's ' $\mathrm{t}$ ' test.

Using this Software, Frequency, Percentage, Mean, Standard Deviation and $\mathrm{P}$ values were calculated. A ' $\mathrm{P}$ ' value of $<0.05$ is taken to denote significant relationship. 


\section{OBSERVATION AND RESULTS}

\section{Demographic Data}

Three study groups were comparable with respect to Age, Weight, Baseline Vital Parameters and Duration of Surgery.

\begin{tabular}{|c|c|c|c|c|c|c|}
\hline \multirow{3}{*}{$\begin{array}{l}\text { Age in } \\
\text { Years }\end{array}$} & \multicolumn{6}{|c|}{ Numbers of Cases in } \\
\hline & \multicolumn{2}{|c|}{ Group S } & \multicolumn{2}{|c|}{ Group F } & \multicolumn{2}{|c|}{ Group M } \\
\hline & No. & $\%$ & No. & $\%$ & No. & $\%$ \\
\hline$<40$ & 1 & 4 & 1 & 4 & 4 & 16 \\
\hline $40-44$ & 6 & 24 & 8 & 32 & 7 & 28 \\
\hline $45-49$ & 9 & 36 & 8 & 32 & 8 & 32 \\
\hline $50-54$ & 7 & 28 & 6 & 24 & 5 & 20 \\
\hline 55 and Above & 2 & 8 & 2 & 8 & 1 & 4 \\
\hline Total & 25 & 100 & 25 & 100 & 25 & 100 \\
\hline Mean & \multicolumn{2}{|c|}{47.2} & \multicolumn{2}{|c|}{46.9} & \multicolumn{2}{|c|}{44.6} \\
\hline SD & \multicolumn{2}{|c|}{4.6} & \multicolumn{2}{|c|}{4.8} & \multicolumn{2}{|c|}{5.5} \\
\hline 'P' & \multicolumn{6}{|c|}{0.3346 (Not Significant) } \\
\hline \multicolumn{7}{|c|}{ Table 1} \\
\hline
\end{tabular}

There is no statistically significant difference in age composition of the three Groups.

\section{Time of Onset of Analgesia}

Time taken to reach the sensory blockade at T10 was as follows -

\begin{tabular}{|c|c|c|c|}
\hline $\begin{array}{c}\text { Time of Onset of } \\
\text { Analgesic (Min) }\end{array}$ & $\begin{array}{c}\text { Group } \\
\text { S }\end{array}$ & $\begin{array}{c}\text { Group } \\
\text { F }\end{array}$ & $\begin{array}{c}\text { Group } \\
\text { M }\end{array}$ \\
\hline Mean & 4.44 & 2.62 & 3.22 \\
\hline SD & 0.65 & 0.39 & 0.36 \\
\hline 'P' & & 0.0001 & 0.0001 \\
\hline \multicolumn{4}{|c|}{ Table 2 } \\
\hline
\end{tabular}

Two Segment Regression Time

\begin{tabular}{|c|c|c|c|}
\hline $\begin{array}{c}\text { 2 Segment Regression } \\
\text { Time (Min) }\end{array}$ & $\begin{array}{c}\text { Group } \\
\text { S }\end{array}$ & $\begin{array}{c}\text { Group } \\
\text { F }\end{array}$ & $\begin{array}{c}\text { Group } \\
\text { M }\end{array}$ \\
\hline Mean & 94.3 & 174.6 & 131.8 \\
\hline SD & 8.6 & 9.6 & 11.4 \\
\hline 'P' & & 0.0001 & 0.0001 \\
\hline \multicolumn{3}{|c|}{ Table 3 } & Significant \\
\hline
\end{tabular}

\section{Duration of Analgesia}

\begin{tabular}{|c|c|c|c|}
\hline $\begin{array}{c}\text { Duration of } \\
\text { Analgesia (Min) }\end{array}$ & $\begin{array}{c}\text { Group } \\
\text { S }\end{array}$ & $\begin{array}{c}\text { Group } \\
\text { F }\end{array}$ & $\begin{array}{c}\text { Group } \\
\text { M }\end{array}$ \\
\hline Mean & 129.4 & 233.8 & 187 \\
\hline SD & 10.8 & 12 & 14 \\
\hline 'P' & & 0.0001 & 0.0001 \\
\hline \multicolumn{4}{|c|}{ Table 4 } \\
\hline
\end{tabular}

\section{Pulse Rate}

\begin{tabular}{|c|c|c|c|}
\hline Pulse Rate & Group S & Group F & Group M \\
\hline Mean & 71.44 & 68.2 & 69.28 \\
\hline SD & 6.67 & 7.72 & 5.25 \\
\hline 'P' & \multicolumn{3}{|c|}{ Not Significant } \\
\hline \multicolumn{3}{|c|}{ Table 5 } \\
\hline
\end{tabular}

There is no statistically significant difference in the $\mathrm{P}$ rate of the three groups.
Systolic BP

\begin{tabular}{|c|c|c|c|}
\hline Systolic BP & Group S & Group F & Group M \\
\hline Mean & 106.4 & 99.4 & 102.2 \\
\hline SD & 94 & 11.2 & 11.3 \\
\hline 'P' & & & 0.147 \\
\hline & \multicolumn{2}{|c|}{ Not Significant } & \\
\hline
\end{tabular}

There is no statistically significant difference in the systolic BP of the three groups.

The patients could void in mean time of $6.3 \mathrm{hrs}$. in Group S, 6.9 hrs. in Group F and 6.6 hrs. in Group M. There were 2 patients in Group $\mathrm{F}$ and 1 patient in Group S and Group M needed intermittent urinary catheterisation. All patients in Group F and Group M were satisfied with Spinal analgesia.

\section{DISCUSSION}

The addition of $20 \mu \mathrm{g}$ Fentanyl and $2 \mathrm{mg}$ Midazolam to hyperbaric Bupivacaine for spinal anaesthesia in patients with lower abdominal gynaecological surgeries improves the quality of intraoperative and postoperative analgesia without increasing the side effects like nausea, vomiting, hypotension, bradycardia or urinary retention.

Fentanyl is a lipophilic opioid with short duration of action, which is more readily eliminated from CSF than hydrophilic opioids, such as morphine.1,2,3 The study conducted at the Department of Anaesthesiology, Tokyo University School of Medicine, Tokyo; and by Dr. Saravnan, Dr. Madankumar, Dr. Balamanimukizhan at Madras Medical College, Chennai shows that intrathecal addition of Fentanyl with Bupivacaine prolongs the intraoperative and postoperative analgesia without serious side effects. ${ }^{4}$ Duration of action of fentanyl may be dose dependent. Hunt et al reported that addition of Fentanyl $>6.25(6.25,12.5,25$, 37 and 50) to hyperbaric bupivacaine was shown to reduce the intraoperative opioid supplement IV from $67 \%$ to $0 \%$ and provide postoperative analgesia of $3-4 \mathrm{hrs}$. in patients who underwent caesarean section under spinal anaesthesia.5,6 In our study, the addition of fentanyl $20 \mu \mathrm{g}$ to bupivacaine in spinal anaesthesia for lower abdominal gynaecological surgeries provided good surgical anaesthesia and postoperative analgesia by an inhibitory action of A-gamma and C-fibre conduction. ${ }^{7}$

The study conducted by Valentine J. M. and coworkers and by Bharathi N, Mohanty P. R., Kaul H. L. in the Dept. of Anaesthesiology and Intensive Care.8,9 All India Institute of Medical Sciences, New Delhi, India, shows that the addition of Midazolam to Bupivacaine intrathecally will prolong the postoperative analgesia. In vitro autoradiography has shown that there is a high density of Benzodiazepine (GABA-A) receptors in lamina-2, of the dorsal horn of spinal cord suggesting a possible role in pain modulation $(18,19)$. Analgesic efficacy of intrathecal midazolam in human has been demonstrated recently. ${ }^{10,11}$ The most serious risk of intrathecal midazolam is its possible neurotoxicity. In vitro studies have suggested that clinically useful doses of intrathecal midazolam are unlikely to be neurotoxic. So far animal studies have revealed no damage to the spinal cord nerve roots or meninges. In addition to the effectiveness of intrathecal midazolam against somatic pain, an antinociceptive against visceral pain has been demonstrated in human after caesarean section.12 Nishiyama et al in 1992 used epidural midazolam along with 
bupivacaine for pain relief in 47 patients who underwent upper abdominal surgery and it was concluded that the optimal dose of midazolam in epidural for postoperative analgesia without producing significant sedation was 0.05 $\mathrm{mg} / \mathrm{kg}$.

\section{Major Advantages have been Observed with the following} Parameters:

1. Time of onset.

Time taken to reach the sensory block at T10 was compared. This was shown to be shortened with addition of Fentanyl and Midazolam. The $\mathrm{P}$ value for the time of onset is found to be statistically significant.

2. Two segment regression time.

It was prolonged with all adjuvant group. The $\mathrm{P}$ value was found to be statistically significant.

0.0001 on comparing Group S and Group F.

0.0001 on comparing Group S and Group M.

3. Duration of analgesia.

It was prolonged with all adjuvant groups compared with control group in a statistically significant manner. The $\mathrm{P}$ value has been found to be -

0.0001 on comparing Group S and Group F.

0.0001 on comparing Group S and Group M.

4. Sedation scale.

On comparing the sedation scale, all adjuvant groups are statistically significant.

\section{Summary}

The study was carried out in 75 patients for lower abdominal gynaecological surgeries. They were divided into 3 groups of 25 each. All groups received injections intrathecally.

Group S received $17.5 \mathrm{mg}$ of $0.5 \%$ Bupivacaine with 0.4 $\mathrm{mL}$ of normal saline.

Group F received $17.5 \mathrm{mg}$ of $0.5 \%$ Bupivacaine with $20 \mu \mathrm{g}$ of Fentanyl ( $0.4 \mathrm{~mL})$.

Group M received $17.5 \mathrm{mg}$ of $0.5 \%$ Bupivacaine with $2 \mathrm{mg}$ of Midazolam (0.4 mL).

Total drug volume in all group was $3.9 \mathrm{~mL}$.

\section{The Comparative Study Demonstrated that -}

1. The addition of Fentanyl Midazolam gives quicker onset of action and prolong the postoperative analgesic time than with the local anaesthetic Bupivacaine alone.

2. Quicker onset of action is more with Fentanyl than with Midazolam.

3. Postoperative analgesic time is more prolonged with Fentanyl and Midazolam group.

4. Midazolam group well sedated and haemodynamically stable.
5. There is no statistically significant difference in pulse rate of the 3 groups.

6. There is no statistically significant difference in systolic BP of the three groups.

7. Pruritus was not recorded in any groups.

\section{CONCLUSION}

Present study revealed the beneficial effect of addition of Fentanyl and Midazolam to Bupivacaine in spinal anaesthesia in lower abdominal gynaecological surgeries. There was significant improvement in intraoperative and postoperative analgesia without any significant side effects.

\section{REFERENCES}

1. Saxena AK, Arava SK. Current concepts in neuraxial administration of opioid and non opioids: an overview and future perspectives. Indian Journal of Anaesthesia 2004;48(1):13-24.

2. Dahlgren G, Halstrand C, Jakobsson J, et al. Intrathecal sufentanyl, fentanyl or placebo added to bupivacaine for cesarean section. Anaesthesia Analg 1997;85(6):128893.

3. Eiseneach JC. Respiratory depression following intrathecal opioids. Anaesthesiology 1991;75(4):712.

4. Chaney MA. Side effects of intrathecal and epidural opioids. Canadian Journal of Anesthesia 1995;42(10):891-903.

5. Cousins MJ, Motler LC. Intrathecal and epidural administarion of opioid. Anaestheiology 1992;61:276310.

6. Wang JK, Nauss LA, Thomas JE. Pain relieved by intrathecally applied morphine in man. Anaesthesiology 1979;50(2):149-51.

7. Yaksh TL, Rudy TA. Analgesia mediated by a direct spinal action of narcotics. Science 1976;192(4246):1357-8.

8. Valentine JM, Lyons G, Bellamy MC. The effect of intrathecal midazolam on post operative pain. European Journal of Anaesthesioligy 1996;13(6):589-93.

9. Serrao JM, Marks RL, Morley SJ, et al. Intrathecal midazolam for the treatment of chronic mechanical low back pain: a controlled comparison with epidural steroid in a pilot study. Pain 1992;48(1):5-12.

10. Faull RL, Villiger JW. Benzodiazepine receptors in the human spinal cord: a detailed anatomical and pharmacological study. Neuroscience 1986;17(3):791802.

11. Goodchild CS, Guo Z, Murgreave A, et al. Antinociception by intrathecal midazolam involves endogenous neurotransmitters acting at spinal cord delta opioid receptors. Br J Anaesth 1996;77(6):758-63.

12. Goodchild CS, Noble J. The effects of intrathecal midazolam on sympathetic nervous system reflexes in man-a pilot study. Br J Cli Pharmocol 1987;23(3):279-85. 